\title{
lonic liquid: green solvent for the synthesis of cellulose/guar gum/PVA biocomposite
}

1 Chandrashekhar M. Patil MSC Research scholar, School of Chemical Sciences, North Maharashtra University, Jalgaon, India

2 Amulrao U. Borse PhD

Professor, School of Chemical Sciences, North Maharashtra University, Jalgaon, India

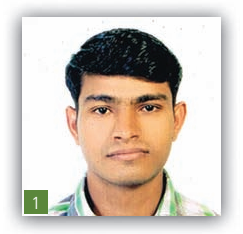

3 Jyotsna S. Meshram PhD

Professor, Department of Chemistry, Rashtrasant Tukadoji Maharaj Nagpur University, Nagpur, India (corresponding author: drjsmeshram@gmail.com)

In recent years, the development of clean, efficient and environmentally friendly chemical processes using less hazardous chemicals has been one of the main goals of researchers. Green chemistry and sustainability are directing the development of the next generation of biocomposite materials and products. Herein, the authors use the ionic liquid 1-butyl-3-methylimidazolium chloride $([\mathrm{BMIM}] \mathrm{Cl})$ as a green solvent for the synthesis of biodegradable, biocomposite materials from cellulose (microcrystalline cellulose (MCC)), guar gum (GG) and poly(vinyl alcohol) (PVA). The effect of GG and PVA composition with MCC was evaluated by comparing the physical, chemical and mechanical characteristics of the produced biocomposite films with those of the regenerated cellulosic film. The tensile strength and hardness of biocomposite films is superior to that of the regenerated cellulosic film. In this method, [BMIM]Cl has been used as a solvent to dissolve and synthesize the MCC/GG/PVA biocomposite material. [BMIM]Cl is removed from the biocomposite material by washing it with ethanol and recovered by using a rotary evaporator. The synthesized biocomposite is an advanced biomaterial with several potential applications in packaging and other fields.

\section{Introduction}

The development of the next generation of eco-friendly biocomposite materials is challenging for researchers because of their potential properties arising from the interaction between other naturally occurring polymers and synthetic polymers. In recent years, biological materials have been used to prepare biocomposite materials - namely, polysaccharides, lipids, proteins and their derivatives. Specifically, within polysaccharides, cellulose derivatives, starch, chitosan, carrageenan, alginate and pectin have received much attention for use as sources of new sustainable and green materials because of their benign properties. Plants, animals, seaweeds and bacteria are known to be sources of natural polysaccharides. ${ }^{1-3} \quad$ Cellulose-based biocomposite materials have come to the attention of researchers because of their eco-friendliness, low cost, renewability, biocompatibility and biodegradable properties. ${ }^{4-6}$ Cellulose is a natural polysaccharide and the most abundant bio-organic polymer on earth; it is composed of many d-glucopyranose units bound by $\beta-1,4-$ glycosidic linkage, with a number of applications, including uses in plastics, textiles, paper, furniture and pharmaceutical products. $^{7-9}$
Guar gum (GG), also called guaran, is a galactomannan derived from the endosperm of Cyamopsis tetragonolobus. The backbone is a linear chain of the $\alpha$-d-galactopyranose unit at the 6-position. It is a natural biopolymer that has been explored for various applications in industries such as food, cosmetics, paper, explosives, textiles, pharmaceuticals, oil recovery and drilling. GG is a non-toxic, easily available, low-cost polysaccharide. Its molecules contain a large number of hydroxyl groups which interact with the hydroxyl groups of the cellulosic molecule. To date, only a few studies on the introduction of GG into cellulosic material have been reported. ${ }^{10-16}$

The poly(vinyl alcohol) (PVA) polymer is a semicrystalline synthetic thermoplastic polymer. It is a water-soluble transparent polymer with a high processability and with excellent chemical and physical properties, biodegradability, non-toxicity and good ability to form films. PVA has many potential applications in technological, pharmaceutical and biomedical fields and the packaging industry. However, the manufacture of the cellulose film is challenging because it is difficult to dissolve it in a common solvent due to strong intra- and intermolecular 
hydrogen bonding. The mechanical properties of cellulose are improved after addition of GG and PVA in ionic liquid. The presence of hydroxyl functionality in PVA and GG results in strong interactions and the formation of intermolecular hydrogen bonds with the hydroxyl group in cellulose, and these provide an additional bonding force to form a biocomposite. It has been reported that the mechanical properties of regenerated cellulose (RC) biocomposites are improved significantly by introducing PVA and GG. Dissolving cellulosic materials and PVA/GG will provide a better composition of the polymer materials and may lead to a biocomposite with optimized properties. ${ }^{17-19}$

Cellulose is insoluble in water and most commercial organic solvents. The solubility problem of cellulose is due to the close chain packing through the numerous intra- and intermolecular hydrogen bonds caused by the presence of hydroxyl groups in cellulose and the high degree of polymerization. ${ }^{20}$ To date, only a limited number of solvent systems used for the dissolution of cellulose have been reported, including N-methylmorpholine-Noxide (NMNO), ( $N, N$-dimethylacetamide/lithium chloride (LiCl)), dimethyl sulfoxide/tetra- $n$-butylammonium fluoride, dimethylformamide/dinitrogen tetroxide $\left(\mathrm{N}_{2} \mathrm{O}_{4}\right)$ and some molten salt hydrates such as lithium perchlorate trihydrate $\left(\mathrm{LiClO}_{4} \cdot 3 \mathrm{H}_{2} \mathrm{O}\right)$. Moreover, these solvent systems sometimes cause serious environmental problems because these solvents evolve a volatile, poisonous gas or waste which cannot be recovered and reused. Due to the environmental problems of using these solvent systems, it became necessarily to develop 'green' cellulose extraction and cellulose dissolution methods. ${ }^{9,21}$

Ionic liquids (ILs), organic salts which melt below $100^{\circ} \mathrm{C}$, have attracted substantial interest as environmentally friendly green alternatives to traditional organic solvents or catalysts because of their attractive properties, such as very low vapor pressure, negligible flammability, high ionic conductivity, high chemical as well as high thermal stability and ease of recyclability. Some research is focused on the dissolution of cellulose by using ILs namely, 1-allyl-3-methylimidazolium chloride and 1-butyl-3methylimidazolium chloride ([BMIM]Cl). ${ }^{22,23}$

The development of eco-friendly composite materials is still a challenging field of research. In the present paper, the authors propose a novel composite system using an eco-friendly material - namely, cellulose - GG and PVA by using ILs. A biocomposite is synthesized using [BMIM] Cl as a green solvent. The solvent is recycled after synthesis of the biocomposite by using a rotary evaporator. The biocomposite is characterized with Fourier transform infrared (FTIR) spectroscopy, X-ray diffraction (XRD) and scanning electron microscopy (SEM). It has been reported that the mechanical properties of biocomposite film are improved significantly by introducing GG and PVA. The aim of the present work is to prepare a novel biocomposite material using an IL as a solvent. The biocomposite material presented in this study is an innovative biomaterial with great possibilities of applications in packaging industries and other fields.

\section{Experimental method}

\subsection{Materials and instrumentation}

1-Methylimidazole and ethyl acetate were procured from SigmaAldrich (Bangalore, India); 1-chlorobutane and microcrystalline cellulose (MCC), from S. D. Fine Chemicals (Mumbai, India); GG, from Spark Chem Laboratories (Mumbai, India); PVA from Loba Chemie Pvt. Ltd (Mumbai, India); and ethanol, from Changshu Yangyuan Chemicals (China).

\subsection{Preparation of 1-n-butyl-3-methylimidazolium chloride}

The IL 1-n-butyl-3-methylimidazolium chloride is synthesized according to a procedure described in the literature. ${ }^{24}$

Equimolar amounts of 1-chlorobutane and 1-methylimidazole are taken and refluxed for $24-72 \mathrm{~h}$ at $70^{\circ} \mathrm{C}$ with constant stirring until two phases were formed. The top phase, containing the unreacted starting material, is decanted, and ethyl acetate (volume approximately equal to half that of the bottom phase) is added with thorough mixing. The ethyl acetate is decanted followed by the addition of fresh ethyl acetate, and this step is repeated twice. The remaining ethyl acetate is removed by heating the bottom phase to $70^{\circ} \mathrm{C}$ and stirring while on a vacuum line. The product, 1-n-butyl-3-methylimidazolium chloride, is slightly yellow crystalline at room temperature $\left(25^{\circ} \mathrm{C}\right)$ and has a melting point of $40^{\circ} \mathrm{C}$. The synthesized 1- $n$-butyl-3-methylimidazolium chloride is characterized using FTIR spectroscopy.

\subsection{Preparation of RC using 1-n-butyl-3- methylimidazolium chloride}

A schematic diagram of the experimental procedure for the preparation of RC material is shown in Figure 1. MCC ( $0.30 \mathrm{~g})$ with [BMIM]Cl $(5 \mathrm{~g})$ is heated and stirred at $100^{\circ} \mathrm{C}$ for $2 \mathrm{~h}$. The resulting homogeneous solution is left at room temperature for $3 \mathrm{~h}$ to form an $\mathrm{MCC} /[\mathrm{BMIM}] \mathrm{Cl}$ gel. The $\mathrm{MCC} /[\mathrm{BMIM}] \mathrm{Cl}$ gel is poured onto a glass plate and kept at room temperature for $24 \mathrm{~h}$. The $\mathrm{MCC} /$ [BMIM] Cl film is immersed in ethanol $(20 \mathrm{ml})$ for $24 \mathrm{~h}$. [BMIM]Cl is soluble in ethanol; the film is removed and dried under reduced pressure for $12 \mathrm{~h}$. The removal of IL from the film is determined from a negative silver nitrate test of chloride ions in the film. $[\mathrm{BMIM}] \mathrm{Cl}$ is separated from ethanol by using a rotary evaporator. $\mathrm{MCC}$ is dissolved in [BMIM]Cl due to the breaking of strong

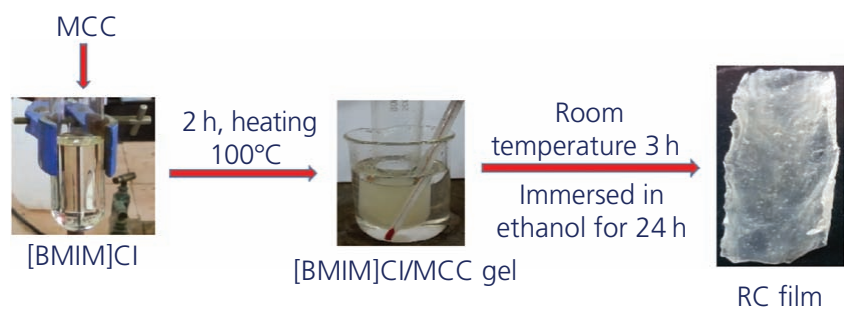

Figure 1. Schematic diagram of the experimental procedure for the preparation of $\mathrm{RC}$ material 
Ionic liquid: green solvent for the synthesis of cellulose/guar gum/PVA biocomposite Patil, Borse and Meshram hydrogen bonds in MCC. The high concentration of chloride ions in ILs, which is highly effective in breaking the extensive hydrogen bonding present in cellulose, plays an important role in its dissolution. The proposed mechanism for the dissolution of MCC in $[\mathrm{BMIM}] \mathrm{Cl}$ is depicted in Figure 2.

\subsection{Preparation of MCC/GG/PVA biocomposite using 1-n-butyl-3-methylimidazolium chloride}

A schematic diagram of the experimental procedure for the preparation of the RC material is shown in Figure 3. MCC $(0.30 \mathrm{~g}), \mathrm{GG}(0.20 \mathrm{~g})$ and PVA $(0.50 \mathrm{~g})$ are dissolved in [BMIM] $\mathrm{Cl}(15 \mathrm{~g})$ by reflux at $100^{\circ} \mathrm{C}$ for $2 \mathrm{~h}$. The resultant viscous solution is cooled at room temperature for $3 \mathrm{~h}$ to form an $\mathrm{MCC} /$ GG/PVA gel-like material. The resulting gel-like material was spread on a petri dish and further kept at room temperature for $48 \mathrm{~h}$. Then, the blend film is immersed in ethanol $(20 \mathrm{ml})$ for $24 \mathrm{~h}$. [BMIM]Cl is soluble in ethanol; the MCC/GG/PVA biocomposite material is removed and dried under reduced pressure for $12 \mathrm{~h}$. $[\mathrm{BMIM}] \mathrm{Cl}$ is separated from ethanol by using a rotary evaporator.

\subsection{Characterization}

The infrared (IR) spectra of the synthesized biocomposite were recorded and characterized by using a Shimadzu FTIR-8400 instrument in the frequency range from 400 to $4000 \mathrm{~cm}^{-1}$ using potassium bromide $(\mathrm{KBr})$ plates. A Bruker Advance 8 X-ray diffractometer and copper $(\mathrm{Cu}) \mathrm{K} \alpha$ radiation were used to obtain the XRD patterns of samples under the conditions of $40 \mathrm{kV}$ and $100 \mathrm{~mA}$ with a copper target. For each interval of $0.02^{\circ}$, the XRD intensity was recorded automatically. The morphology of the dried sample was examined using a scanning electron microscope,

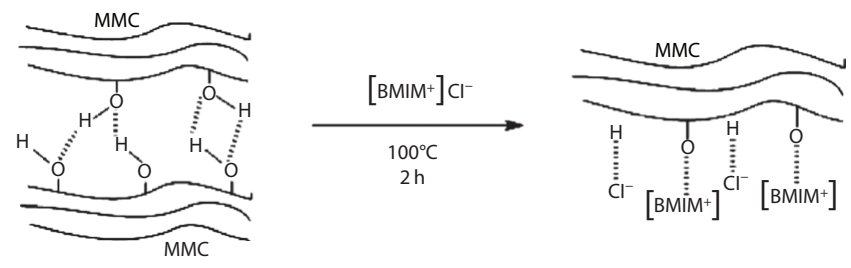

Figure 2. Proposed mechanism for the dissolution of MCC in [BMIM]CI

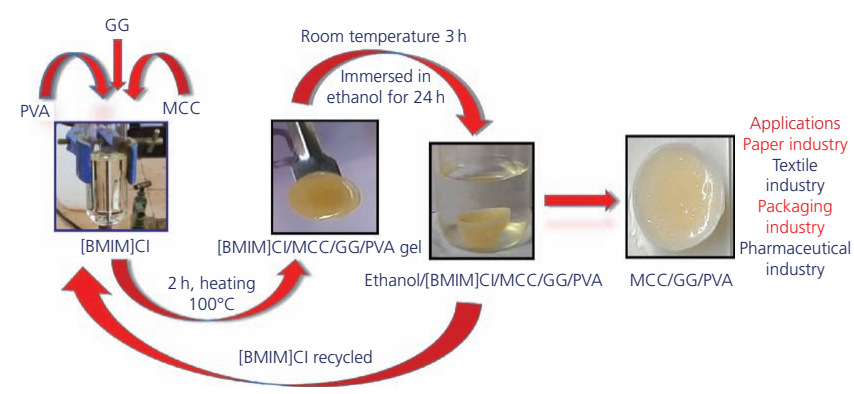

Figure 3. Schematic diagram of the experimental procedure for the synthesis of MCC/GG/PVA composite
S-4800, and Jeol JSM 6360 and JSM 5400 microscopes in the voltage range of $0.5-30 \mathrm{kV}$ after the sample had been coated with a gold film. The mechanical properties of the biocomposite films were evaluated based on their tensile strength and hardness. The tensile strength of the biocomposites present in the dumbbellshaped specimen was determined by using a universal tensile testing machine. The tensile strength, elongation at break and Young's modulus measurements were performed at room temperature. The dumbbell-shaped samples, about $4 \mathrm{~mm}$ thick and $2 \mathrm{~cm}$ long, were tested at a rate of $50 \mathrm{~mm} / \mathrm{min}$. The tensile strength and elongation at break values are the averages of three measurements. A model RR-15 durometer hardness tester was used for testing the hardness of the biocomposites. The flat film samples $(4 \mathrm{~mm})$ were placed on a flat surface, and ten measurements were taken on a different surface of each sample.

\section{Results and discussion}

The main target of the present work is to dissolve cellulose in IL and to prepare an eco-friendly biocomposite; it is difficult to dissolve cellulose in common volatile organic and inorganic solvents. Dissolution of cellulose by using ILs containing chloride ions has been reported in this work. In an IL, the presence of a high concentration of chloride ions is responsible for breaking the intra- and intermolecular hydrogen bonds in cellulose. ${ }^{9,21,22}$

A regenerated cellulosic film is prepared by stirring using a mechanical stirrer at $100^{\circ} \mathrm{C}$ for $2 \mathrm{~h}$. The temperature of the dissolving process is controlled by an oil bath at $100^{\circ} \mathrm{C}$. The homogeneous solution of MCC in ILs is poured onto a glass plate and kept at room temperature to form a uniform film. To remove the IL from the regenerated cellulosic film, it is dissolved in ethanol to obtain a pure cellulosic film. To prepare the biocomposite material, MCC is dissolved in $\mathrm{IL}$ at $100^{\circ} \mathrm{C}$ with vigorous stirring and GG and PVA are added to the homogeneous solution of MCC. After $2 \mathrm{~h}$, the formed gel-like material is poured onto a petri dish to form a film of the biocomposite. The addition of GG and PVA in MCC changes the interfacial properties and morphology of pure MCC. The biocomposite is characterized by FTIR spectroscopy, XRD and SEM.

\subsection{FTIR analysis}

The structure of the synthesized 1-n-butyl-3-methylimidazolium chloride was analyzed by using the FTIR spectra shown in Figure 4. The aliphatic asymmetric and symmetric $\mathrm{C}-\mathrm{H}$ (butane) stretching vibrations were observed at 2970 and $2870 \mathrm{~cm}^{-1}$, respectively, and the bending vibrations of $\mathrm{C}-\mathrm{H}$ (methyl) at $1452 \mathrm{~cm}^{-1}$. The peak at $3078 \mathrm{~cm}^{-1}$ is attributed to $\mathrm{C}=\mathrm{C}-\mathrm{H}$ of the imidazole ring. A broad peak at $3556 \mathrm{~cm}^{-1}$ confirms the formation of a quaternary amine salt with chlorine. The peaks at 1645 and $1590 \mathrm{~cm}^{-1}$ correspond to $\mathrm{C}=\mathrm{C}$ and $\mathrm{C}=\mathrm{N}$ stretching vibrations, respectively. A peak at $1168 \mathrm{~cm}^{-1}$ shows $\mathrm{C}-\mathrm{N}$ stretching vibration. The additional peak observed at 2337 and $2100 \mathrm{~cm}^{-1}$ is due to the potassium bromide moisture.

The FTIR spectra of the MCC/GG/PVA biocomposite and raw materials are shown in Figure 5. In the MCC spectrum, the 
Ionic liquid: green solvent for the synthesis of cellulose/guar gum/PVA biocomposite

Patil, Borse and Meshram

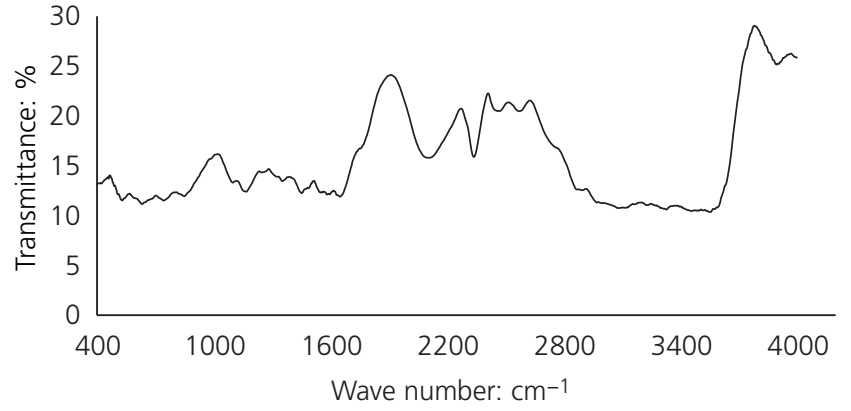

Figure 4. FTIR spectra of [BMIM]CI

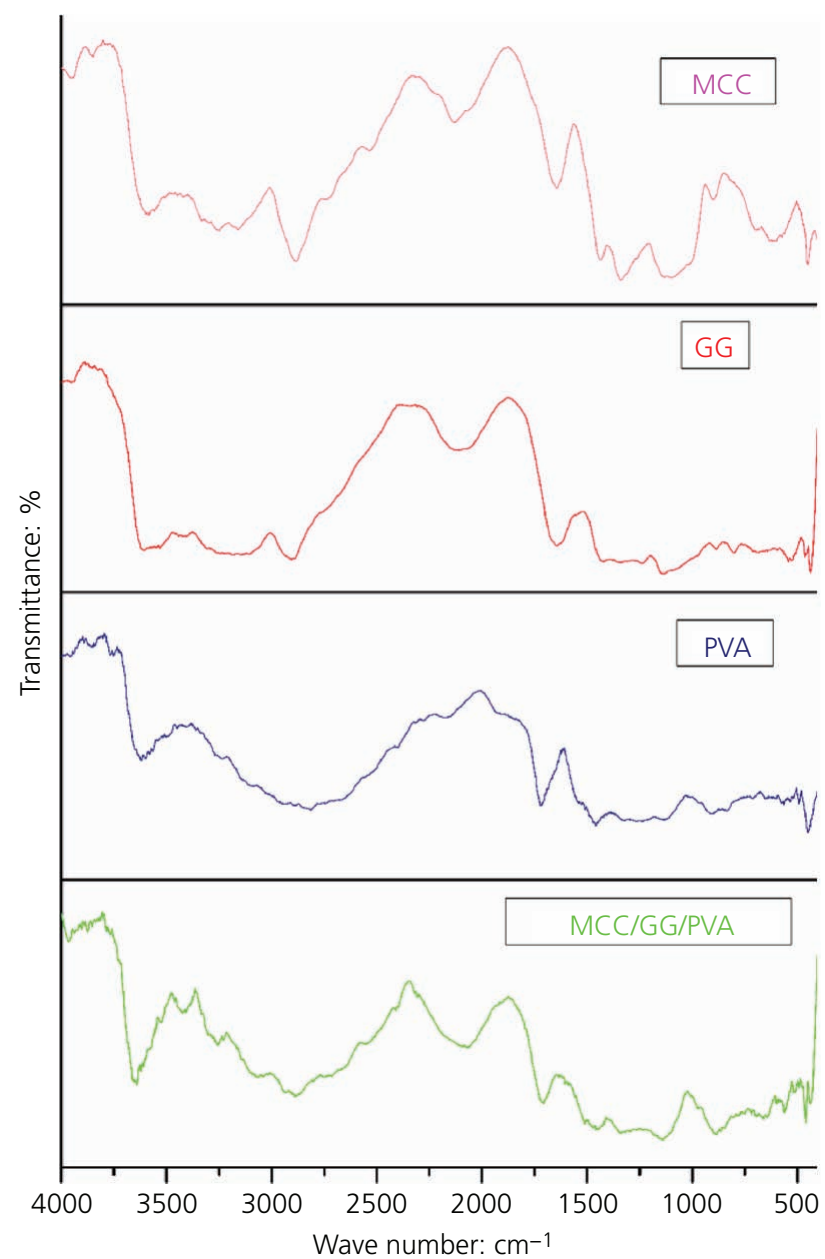

Figure 5. FTIR spectra of MCC, GG, PVA and MCC/GG/PVA composite

absorption peak at $3598 \mathrm{~cm}^{-1}$ is due to the $-\mathrm{OH}$ groups of cellulose, which is shifted to a higher absorption peak $\left(3649 \mathrm{~cm}^{-1}\right)$ in the composite region. The peaks at 2883 and $1095 \mathrm{~cm}^{-1}$ are attributed to $\mathrm{CH}$ and $\mathrm{C}-\mathrm{O}-\mathrm{C}$ stretching vibrations, respectively. The $\mathrm{C}-\mathrm{O}-\mathrm{C}$ stretching vibration shifted to a higher absorption peak at $\left(1144 \mathrm{~cm}^{-1}\right)$ in the composite. The IR spectrum peak of GG bands at the $3615 \mathrm{~cm}^{-1}$ region along with the peaks at 2892 and $1143 \mathrm{~cm}^{-1}$ are due to hydroxyl $(\mathrm{OH}), \mathrm{CH}$ and $\mathrm{C}-\mathrm{O}-\mathrm{C}$ stretching vibrations, respectively. The $\mathrm{OH}$ and $\mathrm{C}-\mathrm{O}-\mathrm{C}$ stretching vibrations shifted to higher absorption peaks (3649 and $1144 \mathrm{~cm}^{-1}$, respectively) in the biocomposite.

The IR spectrum peak of PVA bands at the $3615 \mathrm{~cm}^{-1}$ region along with the peaks at 2811 and $1116 \mathrm{~cm}^{-1}$ are due to hydroxyl $(\mathrm{OH}), \mathrm{CH}$ and $\mathrm{C}-\mathrm{O}-\mathrm{C}$ stretching vibrations, respectively. The $\mathrm{OH}$ and $\mathrm{C}-\mathrm{O}-\mathrm{C}$ stretching vibrations shifted to higher absorption peaks (3649 and $1144 \mathrm{~cm}^{-1}$, respectively) in the composite. This redshift is related to the increasing hydrogen bond interactions between the MCC/GG/ PVA biocomposite among the raw materials. It was also noticed that the relative intensities of the $-\mathrm{CH}$ and $\mathrm{C}-\mathrm{O}-\mathrm{C}$ groups shifted in the MCC/GG/PVA biocomposite.

Assignments of FTIR spectra for the raw materials and MCC/GG/ PVA biocomposites are given in Table 1.

Table 1. Assignments of FTIR spectra for the raw materials and MCC/GG/PVA composite

\begin{tabular}{lcccc} 
& \multicolumn{4}{c}{ Assignment } \\
\cline { 2 - 5 } Wave number: $\mathbf{~ c m}^{-1}$ & MCC & GG & PVA & MCC/GG/PVA \\
\hline VOH & 3598 & 3615 & 3618 & 3649 \\
VCH & 2883 & 2892 & 2811 & 2824 \\
VC-O & 1095 & 1143 & 1116 & 1144 \\
VC=O & - & - & 1718 & 1708
\end{tabular}

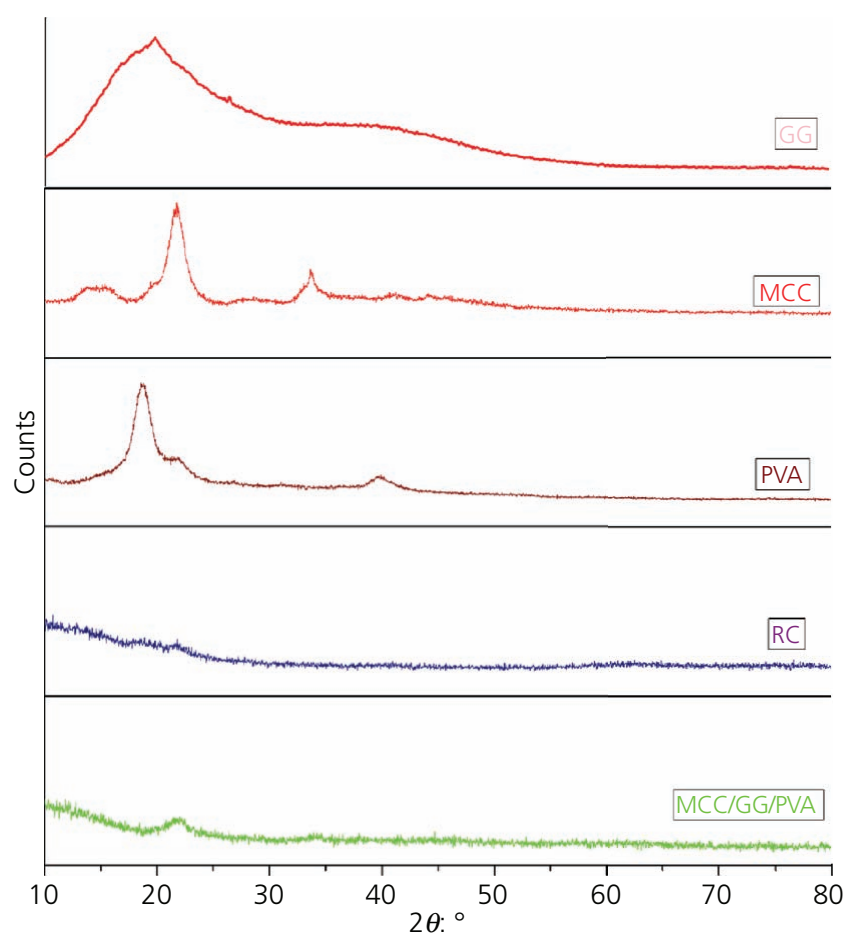

Figure 6. The XRD patterns of the PVA, MCC, RC and (MCC/GG/PVA) composite 
Ionic liquid: green solvent for the synthesis of cellulose/guar gum/PVA biocomposite Patil, Borse and Meshram

\subsection{XRD analysis}

The XRD patterns of the pure MCC and biocomposite materials are illustrated in Figure 6; the XRD pattern of PVA shows a wide diffraction peak at around $18.83^{\circ}$ and a weak diffraction peak at around 21.83 and $39.62^{\circ}$. The crystallographic diffraction patterns of pure MCC showed a broad peak around $15.35^{\circ}$ and two other peaks located at 21.83 and $33.68^{\circ}$. The XRD pattern of GG peaks shows a broad hump in the range of $10 \cdot 20-30 \cdot 86^{\circ}$, which confirms its amorphous structure. ${ }^{25}$ Moreover, based on a comparison of the XRD pattern of the initial cellulose with that of the regenerated cellulosic sample, the diffractogram of the regenerated cellulosic sample clearly shows an amorphous structure. This character is demonstrated by the absence or strong reduction of all peaks corresponding to around $15 \cdot 35,21 \cdot 83$ and $33.68^{\circ}$, which is characteristic of cellulose. The per cent crystallinity of pure MCC, PVA, RC and MCC/GG/PVA is 57. 1, $55 \cdot 4,48 \cdot 9$ and $49 \cdot 1 \%$, respectively. The per cent crystallinity degrees and average size of the crystallite sample were studied before and after dissolution in IL. The degree of the crystallinity of RC and the biocomposite is decreased. Thus, for RC, crystallinity decreases by $8 \cdot 2 \%$, while for the biocomposite film it decreases by $9 \%$. The degree of crystallinity of RC decreases more compared to that of the biocomposite due to the breaking of the intramolecular interaction of cellulose after dissolution in IL, while the degree of crystallinity of MCC/GG/PVA is $8 \%$ lower. The decrease in the degree of crystallinity of $\mathrm{RC}$ and biocomposite can be explained by the strong interaction of MCC with PVA and GG. This result indicates that the MCC/GG/PVA composition has a crystalline and amorphous nature.

\subsection{SEM analysis}

Figure 7 shows the surface morphological changes in the structures of the MCC, GG, PVA and the synthesized MCC/GG/ PVA biocomposite, which are confirmed by SEM. Figure 7(a) shows the structure of MCC, which composed of irregular, flat and rod-like non-aggregated fibers. ${ }^{26,27}$ PVA has a rough surface $^{28}$ (Figure 7(b)). The morphology of pure GG shows a smooth surface and spherical particles ${ }^{29,30}$ (Figures 7(c) and 7(d)). The surface morphology of the MCC/GG/PVA biocomposite (Figures 7(e) and 7(f)) is fractured and irregular. However, the biocomposite material has a fragile, fractured surface. In Figures 7(e) and 7(f) small cavities/voids can be observed on the fractured surface of the biocomposite. The arrows in Figure 7(e) and 7(f) indicate the presence of voids and cavities in the biocomposite. The surface morphology changes are attributed to the hydrogen bonding interactions between $\mathrm{MCC}, \mathrm{GG}$ and PVA that are due to the presence of $-\mathrm{OH}$ functionality. This agrees well with FTIR analysis, which showed that the $\mathrm{OH}$ and

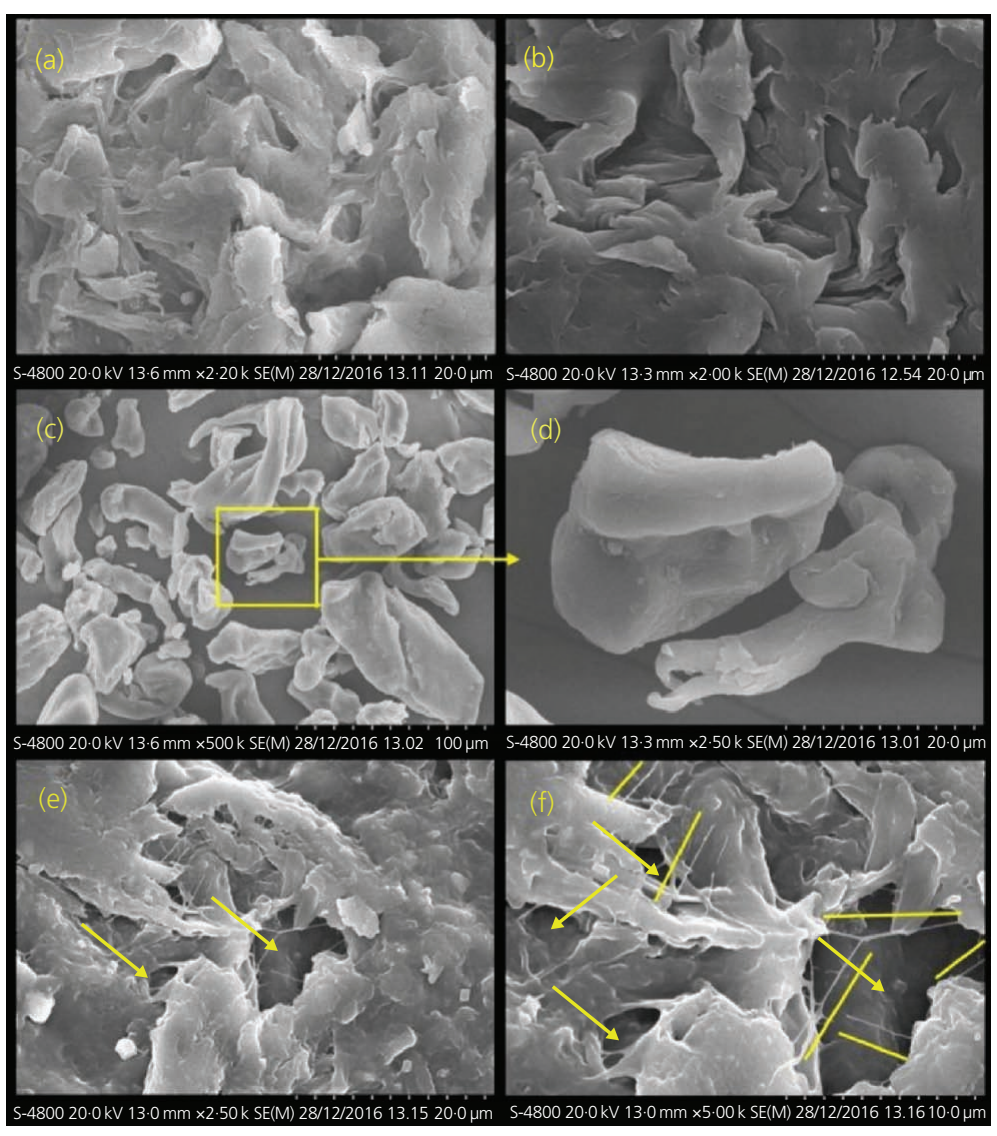

Figure 7. Scanning electron micrographs of (a) MCC, (b) PVA, (c, d) GG and (e, f) MCC/GG/PVA composite 
Table 2. Mechanical properties of the RC film and biocomposite film

\begin{tabular}{|c|c|c|c|c|}
\hline Sample & $\begin{array}{l}\text { Hardness } \\
\text { (Shore D) }\end{array}$ & $\begin{array}{c}\text { Tensile } \\
\text { strength: } \\
\text { kg/cm }\end{array}$ & $\begin{array}{c}\text { Elongation } \\
\text { at break: } \\
\%\end{array}$ & $\begin{array}{c}\text { Young's } \\
\text { modulus: } \\
\mathrm{kg} / \mathrm{cm}^{2}\end{array}$ \\
\hline $\mathrm{RC}$ & 21 & 45.25 & $243 \cdot 15$ & 0.33 \\
\hline Composite fil & $37 \cdot 7$ & 74.88 & $366 \cdot 85$ & 0.4 \\
\hline
\end{tabular}

C-O-C stretching vibrations shifted to higher absorption peaks (3649 and $1144 \mathrm{~cm}^{-1}$, respectively) in the $\mathrm{MCC} / \mathrm{GG} / \mathrm{PVA}$ biocomposite (Figure 5 and Table 1).

\subsection{Mechanical properties}

\subsubsection{Tensile test}

The mechanical properties of the biocomposite were measured at room temperature. The tensile strength of the biocomposite film increased with the addition of GG and PVA compared to that of the regenerated cellulosic film. Table 2 shows the average values of the tensile strength and elongation at break of the biocomposite film. From these results, it can be concluded that the addition of GG and PVA in MCC improves the mechanical properties of biocomposite film. The mechanical properties of the biocomposite film improve because of strong optimal interfacial bonding, interaction between $-\mathrm{OH}$ functionalities and more successful reinforcing effect present in MCC, GG and PVA, while the tensile strength of the regenerated cellulosic film is less due to the weak compactness of MCC.

\subsubsection{Hardness}

The results for the hardness of RC film and biocomposite are presented in Table 2. It was found that the addition of GG and PVA to cellulose has a positive effect on hardness. The hardness of the prepared MCC/GG/PVA biocomposite material increased compared to that of the RC film. This can be explained by the greater frequency of contact between cellulose and GG/PVA, which results in the change in the mechanical properties of the biocomposite.

\section{Conclusion}

The current study has been focused on developing a new approach toward the synthesis of an MCC/GG/PVA biocomposite material using [BMIM]Cl IL as a green solvent. The structure of the biocomposite was successfully characterized by FTIR spectroscopy. The FTIR spectroscopy showed a strong interaction between the biodegradable resources (MCC, GG and PVA). The morphological analysis of the biocomposites containing PVA/GG by SEM showed significant changes in biocomposite morphology. Cellulose/GG/PVA films showed lower crystallinity compared with raw cellulose, as shown by XRD analysis. According to XRD results, the \% crystanality of MCC, GG and PVA has been disrupted in the biocomposite. Favorable interactions between cellulose, GG and PVA affect the mechanical properties of biocomposites. The mechanical properties of the synthesized biocomposite films are superior to those of the regenerated cellulosic film. The aim of the present work is to prepare a novel biocomposite materials using an IL as a solvent. The biocomposite presented here is an advanced biomaterial with several potential applications in packaging and other fields.

\section{REFERENCES}

1. Kiruthika AV, Priyadarzini TR and Veluraja K (2012) Preparation, properties and application of tamarind seed gum reinforced banana fibre composite materials. Fibers and Polymers 13(1): 51-56.

2. Rao MS, Kanatt SR, Chawla SP and Sharma A (2010) Chitosan and guar gum composite films: preparation, physical, mechanical and antimicrobial properties. Carbohydrate Polymers 82(4): 1243-1247.

3. Izawa H and Kadokawa JI (2010) Preparation and characterizations of functional ionic liquid-gel and hydrogel materials of xanthan gum. Journal of Materials Chemistry 20(25): 5235-5241.

4. Borges JP, Godinho MH, Martins AF, Trindade AC and Belgacem MN (2001) Cellulose-based composite films. Mechanics of Composite Materials 37(3): 257-264.

5. Kadokawa Jl, Kato T, Setoyama M and Yamamoto K (2013) Preparation of galactomannan-based materials compatibilized with ionic liquids. Journal of Polymers and the Environment 21(2): 512-519.

6. Prasad K, Mine S, Kaneko Y and Kadokawa JI (2010) Preparation of cellulose-based ionic porous material compatibilized with polymeric ionic liquid. Polymer Bulletin 64(4): 341-349.

7. Wang H, Gurau G and Rogers RD (2012) Ionic liquid processing of cellulose. Chemical Society Reviews 41(4): 1519-1537.

8. Hu X, Wang J and Huang H (2013) Impacts of some macromolecules on the characteristics of hydrogels prepared from pineapple peel cellulose using ionic liquid. Cellulose 20(6): 2923-2933.

9. Pal S, Patra AS, Ghorai S et al. (2015) Modified guar gum $/ \mathrm{SiO}_{2}$ : development and application of a novel hybrid nanocomposite as a flocculant for the treatment of wastewater. Environmental Science: Water Research \& Technology 1(1): 84-95.

10. Shenoy MA and Melo DJ (2007) Evaluation of mechanical properties of unsaturated polyester guar gum/hydroxypropyl guar gum composites. eXPRESS Polymer Letters 1(9): 622-628.

11. Wang $W$, Zheng $Y$ and Wang A (2008) Syntheses and properties of superabsorbent composites based on natural guar gum and attapulgite. Polymers for Advanced Technologies 19(12): 1852-1859.

12. Sharma S, Kaur J, Sharma G et al. (2013) Preparation and characterization of $\mathrm{pH}$-responsive guar gum microspheres. International Journal of Biological Macromolecules 30(62): 636-641.

13. Ranjan JK, Mahato K and Goswami S (2013) Mechanical and morphological properties of vinyl ester/guar gum treated sisal fibre composites. International Journal of Engineering Research and Technology 2(11): 2530-2543.

14. Wang W and Wang A (2009) Synthesis and swelling properties of guar gum-g-poly(sodium acrylate)/Na-montmorillonite superabsorbent nanocomposite. Journal of Composite Materials 43(23): 2805-2819.

15. Mudgil D, Barak S and Khatkar BS (2014) Guar gum: processing, properties and food applications - a review. Journal of Food Science and Technology 51(3): 409-418.

16. Anju VP and Narayanankutty SK (2016) Polyaniline coated cellulose fiber/polyvinyl alcohol composites with high dielectric permittivity and low percolation threshold. AIP Advances 6(1): 015109.

17. Samzadeh-Kermani A, Mirzaee $M$ and Ghaffari-Moghaddam M (2016) Polyvinyl alcohol/polyaniline/ZnO nanocomposite: synthesis, characterization and bactericidal property. Advances in Biological Chemistry 6(1): 1-11.

18. Mohamoud MA (2013) Polyaniline/poly (vinyl alcohol)(PAN/PVA) composite films: the synergy of film structural stiffening, redox amplification, and mobile species compositional dynamics. Journal of Solid State Electrochemistry 17(11): 2771-2782.

19. Kadokawa Jl, Hirohama K, Mine S, Kato T and Yamamoto K (2012) Facile preparation of chitin/cellulose composite films using ionic liquids. Journal of Polymers and the Environment 20(1): 37-42. 
Green Materials

Volume 6 Issue GMAT1
Ionic liquid: green solvent for the synthesis of cellulose/guar gum/PVA biocomposite

Patil, Borse and Meshram
20. Zhu S, Wu Y, Chen Q et al. (2006) Dissolution of cellulose with ionic liquids and its application: a mini-review. Green Chemistry 8(4): 325-327.

21. Swatloski RP, Spear SK, Holbrey JD and Rogers RD (2002) Dissolution of cellose with ionic liquids. Journal of the American Chemical Society 124(18): 4974-4975.

22. Montanino M, Moreno M, Alessandrini F et al. (2012) Physical and electrochemical properties of binary ionic liquid mixtures: $(1-x)$ PYR $_{14}$ TFSI- $(x)$ PYR $_{14} \mathrm{IM}_{14}$. Electrochimica Acta 60: 163-169.

23. Domańska U (2010) Physico-chemical properties and phase behaviour of pyrrolidinium-based ionic liquids. International Journal of Molecular Sciences 11(4): 1825-1841.

24. Huddleston JG, Visser AE, Reichert WM et al. (2001) Characterization and comparison of hydrophilic and hydrophobic room temperature ionic liquids incorporating the imidazolium cation. Green Chemistry 3(4): $156-164$

25. Kumar A, De A and Mozumdar S (2015) Synthesis of acrylate guargum for delivery of bioactive molecules. Bulletin of Materials Science 38(4): 1025-1032.
26. Karim MZ, Chowdhury ZZ, Hamid SB and Ali ME (2014) Statistical optimization for acid hydrolysis of microcrystalline cellulose and its physiochemical characterization by using metal ion catalyst. Materials 7(10): 6982-6999.

27. Haque SM, Chowdhury AA, Rana AA et al. (2015) Synthesis of microcrystalline cellulose from pretreated cotton obtained from Bombax ceiba L. and its characterization. Bangladesh Journal of Scientific and Industrial Research 50(3): 199-204.

28. Baptista JG, Rodrigues SP, Matsushita AF et al. (2016) Does poly(vinyl alcohol) act as an amphiphilic polymer? An interaction study with simvastatin. Journal of Molecular Liquids 222: 287-94.

29. Sharma R, Kaith BS, Kalia S et al. (2015) Biodegradable and conducting hydrogels based on Guar gum polysaccharide for antibacterial and dye removal applications. Journal of Environmental Management 162: 37-45.

30. Wang Q, Ellis PR and Ross-Murphy SB (2003) Dissolution kinetics of guar gum powders - II. effects of concentration and molecular weight. Carbohydrate Polymers 53(1): 75-83.

\section{How can you contribute?}

To discuss this paper, please submit up to 500 words to the journal office at journals@ice.org.uk.Your contribution will be forwarded to the author(s) for a reply and, if considered appropriate by the editor-in-chief, it will be published as a discussion in a future issue of the journal.

ICE Science journals rely entirely on contributions from the field of materials science and engineering. Information about how to submit your paper online is available at www.icevirtuallibrary.com/page/authors, where you will also find detailed author guidelines. 